\title{
The relationship between facial skeleton morphology and bite force in people with a normal relation of the bases of jaws and skull
}

\author{
Ł. Sidorowicz ${ }^{1}$, J. Szymańska² \\ ${ }^{1}$ Chair and Department of Jaw Orthopaedics, Medical University of Lublin, Poland \\ ${ }^{2}$ Chair and Department of Paedodontics, Medical University of Lublin, Poland
}

[Received 26 February 2015; Accepted 28 March 2015]

Background: Better knowledge on the relationship between craniofacial structure and bite force may serve as a reference point for prophylactic and therapeutic activities targeted at developmental age patients. The aim of the study was to assess the correlation between facial skeletal morphology and bite force.

Materials and methods: The study included 54 subjects aged 7-16 years with a normal relation of the bases of jaws and skull, according to Segner's and Hasund's analysis standards (ML-NL and ML-NSL angles values were $20.0 \pm 7.0^{\circ}$ and $28.0 \pm 5.0^{\circ}$, respectively). The study group included patients who volunteered to diagnosis and possible orthodontic treatment. Bite force was tested with a digital dynamometer calibrated in Newtons. The measurement was performed at the level of the first permanent molars. Cephalometric analysis was based on lateral cephalometric radiographs. The vertical relations were assessed using the following measurements: ML-NSL, ML-NL, NL-NSL, N-Me, Sp-Me, SpMe:NMe, ms-NL, SGo:NMe.

Results: Bite force does not depend on the following factors: lower anterior face height (Sp-Me), lower anterior face height to total anterior face height ratio (SpMe:NMe), posterior to anterior face height ratio (SGO:NMe), and the value of ML-NL, ML-NSL and NL-NSL angles.

Conclusions: The posterior height of the maxilla alveolar process (ms-NL) exerts the greatest influence on bite force in people with a normal relation of the bases of jaws and skull: with an increase in ms-NL value bite force is reduced. (Folia Morphol 2015; 74, 4: 508-512)

Key words: facial morphology, Segner's and Hasund's analysis standards, cephalometric analysis

\section{INTRODUCTION}

Numerous papers discuss bite forces, morphology, thickness and muscle activity and their impact on facial skeleton morphology $[2,5,11,14]$. Only a few studies, however, have attempted to investigate in detail the relationship between bite force and facial morphology described by a cephalometric analysis $[4,8,9,12,15]$. It must be noted that the fact of researchers using different methods and standards of cephalometric interpretation creates additional difficulties in analysing and comparing results. The aim of the study was to assess the correlation

Address for correspondence: Prof. J. Szymańska, Chair and Department of Paedodontics, Medical University of Lublin, ul. Karmelicka 7, 20-018 Lublin, Poland, e-mail: szymanska.polska@gmail.com 
between craniofacial structure morphology, described with selected parameters of cephalometric analysis, and bite force.

\section{MATERIALS AND METHODS}

The studied subjects (54 patients of the Department and Chair of Maxillofacial Orthopaedics, Medical University of Lublin, Poland) aged 7-16 years referred to the clinic for diagnosis and possible orthodontic treatment. The mean age of the patients ( 27 boys and 27 girls) was $12.2 \pm 1.8$ years; half of the study population did not exceed 12 years of age.

The study included patients who met the following criteria:

- had no history and received no orthodontic treatment at the time of the study;

- had lateral cephalometric radiographs performed;

- were in overall good health condition without developmental impairments and muscular system disorders.

Another criterion of inclusion of a patient in the study group was the value of mandibular jaw base line and maxillary jaw-base line (ML-NL) and mandibular jaw-baseline and the anterior cranial base line (ML-NSL) angles according to the standards of the Segner's and Hasund's analysis [10]. In the study group, ML-NL angle was $20.0 \pm 7.0^{\circ}$ and ML-NSL angle was $28.0 \pm 5.0^{\circ}$. Bite forces were tested using a digital dynamometer (Imada, Japan, type ZPS-LM$-2000 N)$. The device was calibrated in Newtons - N (SI unit of force), its range being 1-2000 N. The measurement was performed at the level of the first permanent molars. The patient was instructed to bite the prepared recorder with maximum force. The dynamometer, set to 'peak' mode, recorded and displayed the highest registered value. The measurement was repeated 5 times at a 2-min interval, for both the right and the left side. The highest recorded value (maximum bite force) and the mean value of all measurements were included in the analysis. The results were expressed in Newtons (N).

The lateral cephalometric radiographs were taken with X-ray PROSCAN (PLANMECA), at voltage of $70 \mathrm{kV}$ and the exposure time of $0.65 \mathrm{~s}$, using a lamp set at $1.52 \mathrm{~m}$ from the patient's head. With the sagittal plane parallel to the X-ray film and the head in natural position, right lateral radiographs were obtained. The images were subject to cephalometric analysis with specialist computer software (Ortobajt), after the necessary cephalometric points had been marked on the

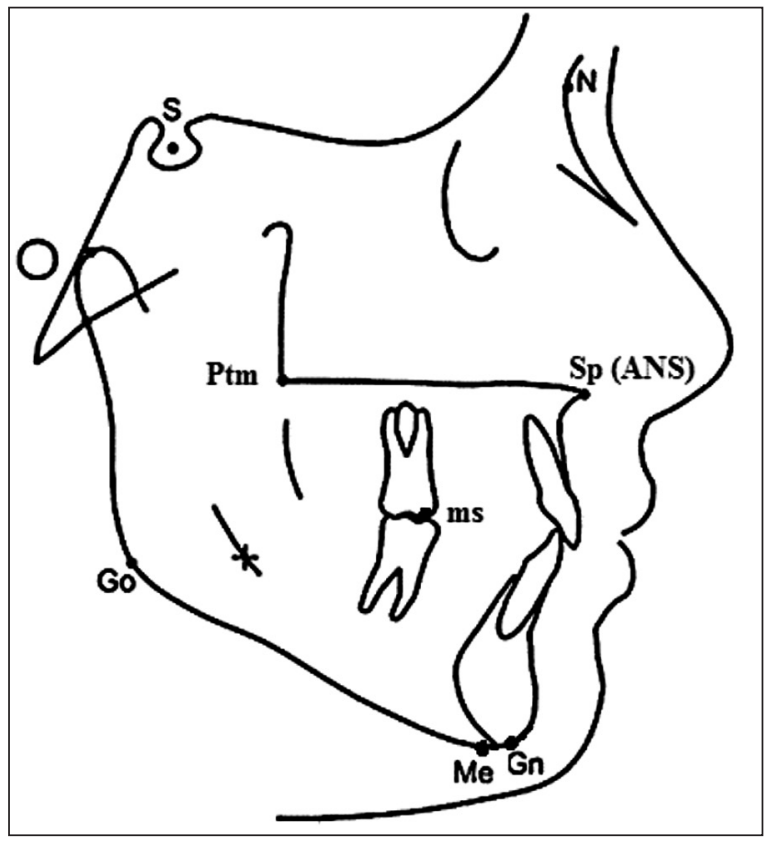

Figure 1. Measuring points; abbreviations — see text

screen. In addition, some measurement points were put manually on tracing paper with a $0.3 \mathrm{~mm}$ pencil. The points identified and marked on each evaluated cephalogram are shown in Figure 1.

The following reference lines were determined on the basis of the marked points:

- NSL - the anterior cranial fossa line between points $\mathrm{S}$ and $\mathrm{N}$;

- NL - the maxillary plane line between points $\mathrm{Sp}$ (ANS) and Ptm;

- ML - the mandibular plane line between points Go and Gn.

To evaluate vertical relationships the following measurements were used:

- ML-NSL angle - the inclination of the mandible to the anterior cranial fossa;

- ML-NL angle - the inclination of the mandible to the maxillary plane;

- NL-NSL angle - the inclination of the maxillary plane to the anterior cranial base;

- N-Me distance - total anterior facial height;

- Sp-Me distance - lower anterior facial height;

- SGo:NMe ratio - the ratio of posterior to anterior face height expressed in percent;

- SpMe:NMe ratio - the ratio of anterior lower to total anterior face height expressed in per cent;

- ms-NL distance - the posterior height of the maxilla alveolar process. 
Table 1. Characteristics of analysed parameters in the study group

\begin{tabular}{lcccccc}
\hline Study group & Mean & Median & Minimum & Maximum & $\begin{array}{c}\text { Standard } \\
\text { deviation }\end{array}$ & $\begin{array}{c}\text { Coefficient } \\
\text { of variation }\end{array}$ \\
\hline NL-NSL & 6.23 & 5.7 & 0.7 & 12.3 & 2.9 & 45.8 \\
ML-NSL & 28.39 & 29.8 & 19.2 & 32.9 & 3.5 & 12.4 \\
ML-NL & 22.16 & 22.3 & 12.3 & 29.0 & 3.9 & 17.8 \\
ms-NL & 22.54 & 23.0 & 16.0 & 28.0 & 2.5 & 11.3 \\
SGo:NMe & 67.74 & 67.2 & 59.2 & 75.7 & 3.4 & 5.0 \\
N-Me & 114.87 & 113.0 & 104.0 & 131.0 & 5.6 & 4.9 \\
Sp-Me & 62.67 & 63.0 & 52.0 & 68.0 & 3.9 & 6.3 \\
SpMe:NMe & 54.53 & 55.1 & 44.0 & 62.5 & 4.2 & 7.7 \\
Maximum bite force on the left side & 340.83 & 359.0 & 115.0 & 478.0 & 84.2 & 24.7 \\
Maximum bite force on the right side & 341.46 & 339.5 & 150.0 & 511.0 & 93.5 & 27.4 \\
Mean bite force on the left side & 289.67 & 308.0 & 82.0 & 411.0 & 73.6 & 25.4 \\
Mean bite force on the right side & 284.98 & 287.5 & 98.0 & 450.0 & 87.4 & 30.7 \\
\hline
\end{tabular}

Abbreviations - see text

$\mathrm{N}-\mathrm{Me}$, Sp-Me, SpMe:NMe and ms-NL were measured manually on the contour of the cephalometric radiographs, while other measurements were made with the Ortobajt software.

\section{Statistical analysis}

The obtained results were analysed statistically. The values of the analysed parameters measured in nominal scale were characterised in terms of cardinality and percentage, while those measured in ratio scale were characterised with arithmetic mean, standard deviation and range of variation. The relationship between the measured parameters was established using the Pearson correlation coefficient, while for statistically significant relationships straight regression lines were determined. The parameters of the regression equation were assessed with the method of least squares, which is a simple generalisation of the method used in the case of simple linear regression. The goodness of fit was evaluated using the multiple determination coefficient $R^{2}$. A 5\% error of inference and a related significance level $p<0.05$, to indicate the significant relationships or differences, were assumed. The software used to prepare the databases and perform statistical analyses was Statistica 10.0.

The study was approved by The Medical University of Lublin Ethical Committee (Resolution No. KE-0254/9/2013).

\section{RESULTS}

Table 1 presents the characteristics of the analysed parameters in the study group. The statistically significant relationships between the elements of cephalometric analysis and bite force are discussed in the paper. It should be noted, however, that the statistically non-significant parameters that did not affect bite force included: lower anterior face height (Sp-Me), lower anterior face height to total face height ratio (SpMe:NMe), posterior face height to anterior face height ratio (SG0:NMe), ML-NL, ML-NSL and NL-NSL angles.

A statistically significant, moderate negative correlation was found between bite force and the posterior height of the maxilla alveolar process (ms-NL), i.e. bite force decreases with an increase in ms-NL value (Table 2).

The estimation of regression coefficient, with ms-NL as a variable, indicates that an increase in the value of ms-NL by $1 \mathrm{~mm}$ may result in a decrease in the mean bite force on the left side by $17.2 \mathrm{~N}$, while on the right side - by $19.65 \mathrm{~N}$. However, an analysis of the impact of ms-NL on the maximum bite force on the left and right showed that an increase by $1 \mathrm{~mm}$ in ms-NL is likely to cause a decrease in the maximum bite force on the left by $20.1 \mathrm{~N}$, and by $24.2 \mathrm{~N}$ on the right side.

A statistically significant correlation between bite force and total anterior facial height (N-Me) was found only on the left side, both for mean and maximum values. The analysed relationships on the right side were statistically non-significant (Table 3).

The detected relationship was a weak negative correlation, i.e. with a decrease in total anterior facial height ( $\mathrm{N}-\mathrm{Me})$, bite force increased. The estimation of regression coefficient, with $\mathrm{N}-\mathrm{Me}$ as a variable, 
Table 2. The relationship between bite force and the posterior height of the maxilla alveolar process (ms-NL) distance in the study group

\begin{tabular}{lcc}
\hline Studied parameters & Test results & Statistical significance \\
\hline Relationship between mean bite force on the left side and $\mathrm{ms}-\mathrm{NL}$ & $\mathrm{t}=-4.08 ; \mathrm{p}<0.05 ; \mathrm{r}=-0.50$ & Statistically significant \\
Relationship between mean bite force on the right side and $\mathrm{ms}-\mathrm{NL}$ & $\mathrm{t}=-3.72 ; \mathrm{p}<0.05 ; \mathrm{r}=-0.46$ & Statistically significant \\
Relationship between maximum bite force on the left side and $\mathrm{ms}-\mathrm{NL}$ & $\mathrm{t}=-4.29 ; \mathrm{p}<0.05 ; \mathrm{r}=-0.51$ & Statistically significant \\
Relationship between maximum bite force on the right side and $\mathrm{ms}-\mathrm{NL}$ & $\mathrm{t}=-5.17 ; \mathrm{p}<0.05 ; \mathrm{r}=-0.58$ & Statistically significant \\
\hline
\end{tabular}

$\mathrm{p}$ - significance level; $r$ - Pearson correlation coefficient; $t$ - valve of the test function

Table 3. The relationship between bite force and total anterior facial height (N-Me) in the study group

\begin{tabular}{lcc}
\hline Studied parameters & Test results & Statistical significance \\
\hline Relationship between mean bite force on the left side and N-Me & $t=-2.10 ; p<0.05 ; r=-0.28$ & Statistically significant \\
Relationship between maximum bite force on the left side N-Me & $t=-2.06 ; p<0.05 ; r=-0.27$ & Statistically significant \\
\hline
\end{tabular}

$\mathrm{p}$ - significance level; $r$ - Pearson correlation coefficient; $t$ - valve of the test function

indicates that with an increase in N-Me by $1 \mathrm{~mm}$, a decrease in the mean value of bite force on the left by $3.7 \mathrm{~N}$ can be expected. An even more dynamic change can be observed for the maximum bite force on the left. An increase in $\mathrm{N}$-Me by $1 \mathrm{~mm}$ reduces bite force on average by $4.1 \mathrm{~N}$.

In addition, using multiple linear regression analysis, i.e. the stepwise forward method, models were built to examine the influence exerted by the analysed variables on the mean and maximum bite force on the left and right sides in people with a normal relation of the bases of jaws and skull. The following models were defined for:

- the mean bite force on the left side: mean bite force on the left $=842.41-16.16 \times$ ms-NL $\left(R^{2}=36.7 \% ; F=14.79 ; p<0.00001\right)$;

- the mean bite force on the right side: mean bite force on the right $=628.66-19.14 \times \mathrm{ms}-\mathrm{NL}$ $\left(R^{2}=34.94 \% ; F=13.69 ; p<0.00002\right) ;$

- the maximum bite force on the left side: maximum bite force on the left $=973.85-17.55 \times$ ms-NL $\left(R^{2}=41.39 \% ; F=11.77 ; p<0.00001\right)$;

- the maximum bite force of the right side: maximum bite force on the right $=795.69-23.76 \times \mathrm{ms}-\mathrm{NL}$ $\left(R^{2}=45.15 \% ; F=20.99 ; p<0.00000\right)$, where $R^{2}$ - coefficient of determination (fit), $\mathrm{F}$ - statistic value, $\mathrm{p}$ - test probability level.

The documentation of the models is available from the authors.

\section{DISCUSSION}

In earlier studies, other authors found a statistically significant correlation between the posterior height of the alveolar process and the maximum bite force. Interestingly, it was a positive correlation, i.e. with an increasing $\mathrm{ms}-\mathrm{NL}$ bite force also increased $[1,12]$; those results, however, were described by Braun et al. [1] as "unexpected". Also Ingervall and Minder [4], as well as Kovero et al. [8] found a statistically significant, positive correlation between ms-NL and bite force, but only in female patients. In the male group, however, the correlation between the variables, although not statistically significant, was negative [8]. The means for ms-NL of the girls examined by Ingervall and Minder [4] were $19.4 \pm$ $\pm 2.1 \mathrm{~mm}$. These results are significantly lower than the values obtained in our research, despite the similar age of patients participating in the study.

In our study a weak negative correlation was found between the mean and maximum bite force and $\mathrm{N}-\mathrm{Me}$ in the study group only on the left side. Other authors did not record any statistically significant relationship between $\mathrm{N}-\mathrm{Me}$ and bite force value, either in adult women, whose mean N-ME value was $121.4 \pm 6.6 \mathrm{~mm}$ [12], or in patients aged 7-13 years, whose mean $\mathrm{N}$-Me value was $110 \pm 6.9 \mathrm{~mm}$, i.e. lower than in our study [13]. Also the research by Uchida et al. [15] did not confirm any statistically significant difference between total anterior facial height and bite force in patients aged 17-41 years, whose mean $\mathrm{N}-\mathrm{Me}$ value was $132 \pm 7.4 \mathrm{~mm}$. These results are consistent with the reports by Kiliaridis et al. [6] and Koc et al. [7], who took the measurements on the photographs of patients' faces, and not on the cephalographic radiographs.

Different results were obtained by Van Sprosen et al. [17], who found a statistically significant rela- 
tionship between $\mathrm{N}-\mathrm{Me}$ value and the cross-section of masseter muscles which, according to many scholars, is closely related to bite force $[3,16]$. They showed that with an increase in N-Me segment, the cross-section of masseter muscles, and thus bite force, decreases.

\section{CONCLUSIONS}

It summary, it must be concluded that out of the selected elements of craniofacial structure, the posterior height of the maxilla alveolar process (ms-NL) exerts the greatest influence on bite force in patients with a normal relation of the bases of jaws and skull, and that with an increase in ms-NL value bite force is reduced. However, the influence of an increase in total anterior face height on a decrease in the mean and maximum bite force on the left side, found in subjects with a normal relation of the bases of jaws and skull, requires further investigation.

\section{REFERENCES}

1. Braun S, Bantleon HP, Hnat WP, Freudenthaler JW, Marcotte MR, Johnson BE (1995) A study of bite force, part 2: Relationship to various cephalometric measurements. Angle Orthod, 65: 373-377.

2. Ciccone de Faria Tdos S, Hallak Regalo SC, Thomazinho A, Vitti M, de Felício CM (2010) Masticatory muscle activity in children with a skeletal or dentoalveolar open bite. Eur J Orthod, 32: 453-458.

3. Goto TK, Yahagi M, Nakamura Y, Tokumori K, Langenbach GE, Yoshiura K (2005) In vivo cross-sectional area of human jaw muscles varies with section location and jaw position. J Dent Res, 84: 570-575.

4. Ingervall B, Minder C (1997) Correlation between maximum bite force and facial morphology in children. Angle Orthod, 67: 415-422.

5. Kiliaridis S, Georgiakaki I, Katsaros C (2003) Masseter muscle thickness and maxillary dental arch width. Eur J Orthod, 25: 259-263.
6. Kiliaridis S, Kjellberg H, Wenneberg B, Engström C (1993) The relationship between maximal bite force, bite force endurance, and facial morphology during growth. A cross-sectional study. Acta Odontol Scand, 51: 323-331.

7. Koc D, Dogan A, Bek B (2010) Bite force and influential factors on bite force measurements: a literature review. Eur J Dent, 4: 223-232.

8. Kovero O, Hurmerinta K, Zepa I, Huggare J, Nissinen M, Könönen M (2002) Maximal bite force and its associations with spinal posture and craniofacial morphology in young adults. Acta Odontol Scand, 60: 365-369.

9. Lowe AA, Takada K, Taylor LM (1983) Muscle activity during function and its correlation with craniofacial morphology in a sample of subjects with Class II, Division 1 malocclusions. Am J Orthod, 84: 204-211.

10. Segner D, Hasund A (1996) Indywidualna kefalometria. Med Tour Press International, Warszawa.

11. Shinkai RS, Lazzari FL, Canabarro SA, Gomes M, Grossi ML, Hirakata LM, Mota EG (2007) Maximum occlusal force and medial mandibular flexure in relation to vertical facial pattern: a cross-sectional study. Head Face Med, 2: 3-18.

12. Sondang P, Kumagai $\mathrm{H}$, Tanaka E, Ozaki H, Nikawa H, Tanne K, Hamada T (2003) Correlation between maximum bite force and craniofacial morphology of young adults in Indonesia. J Oral Rehabil, 30: 1109-1117.

13. Sonnesen L, Bakke M (2005) Molar bite force in relation to occlusion, craniofacial dimensions, and head posture in pre-orthodontic children. Eur J Orthod, 27: 58-63.

14. Tuxen A, Bakke M, Pinholt EM (1999) Comparative data from young men and women on masseter muscle fibres, function and facial morphology. Arch Oral Biol, 44: 509-518.

15. Uchida Y, Motoyoshi M, Shigeeda T, Shinohara A, Igarashi Y, Sakaguchi M, Shimizu N (2011) Relationship between masseter muscle size and maxillary morphology. Eur J Orthod, 33: 654-659.

16. Ueki K, Takazakura D, Marukawa K, Shimada M, Nakagawa K, Yamamoto E (2006) Relationship between the morphologies of the masseter muscle and the ramus and occlusal force in patients with mandibular prognathism. J Oral Maxillofac Surg, 64: 1480-1486.

17. Van Spronsen PH, Weijs WA, Valk J, Prahl-Andersen B, van Ginkel FC (1992) A comparison of jaw muscle cross-sections of long-face and normal adults. J Dent Res, 71: 1279-1285. 